\title{
Article \\ Evaluation of Rural Landscape Resources Based on Cloud Model and Probabilistic Linguistic Term Set
}

\author{
Weiwen Li ${ }^{1}$, Yijiang Zhou ${ }^{2}$ and Ge Xun ${ }^{3, *}$ \\ 1 College of Landscape Architecture, Central South University of Forestry and Technology, \\ Changsha 410004, China; 20181200161@csuft.edu.cn \\ 2 School of Business Administration, Hunan University, Changsha 410082, China; zhouyijiang1999@hnu.edu.cn \\ 3 School of Economics, Central South University of Forestry and Technology, Changsha 410004, China \\ * Correspondence: xunge6486999@163.com
}

Citation: Li, W.; Zhou, Y.; Xun, G. Evaluation of Rural Landscape

Resources Based on Cloud Model and Probabilistic Linguistic Term Set. Land 2022, 11, 60. https://doi.org/ 10.3390/land11010060

Academic Editor: Audrey L. Mayer

Received: 22 September 2021

Accepted: 30 December 2021

Published: 1 January 2022

Publisher's Note: MDPI stays neutral with regard to jurisdictional claims in published maps and institutional affiliations.

Copyright: (c) 2022 by the authors. Licensee MDPI, Basel, Switzerland. This article is an open access article distributed under the terms and conditions of the Creative Commons Attribution (CC BY) license (https:// creativecommons.org/licenses/by/ $4.0 /)$.

\begin{abstract}
Rural landscape resources are important ingredients of rural revitalization and modernization in developing countries and regions. Evaluation methods play a crucial role in the development planning, design, transformation, and protection of these resources. However, there has been a lack of research on the evaluation of rural landscape resources, especially from the perspective of rural revitalization. Based on previous evaluation methods and expert consultations on landscape planning and design, we proposed a new approach for evaluating rural landscape resources by establishing a new index system and using the Analytic Hierarchy Process (AHP) and probabilistic linguistic Cloud Model. To demonstrate its applicability and effectiveness, we applied our model to the case of a village (Xiapu) in Guangdong, China, determined the parameter set of its rural landscape resources, and obtained related results showing that the method is practical and can reflect the value of resources objectively and efficiently. Based on this model, further suggestions are provided to improve the design and other utilizations of rural landscape resources.
\end{abstract}

Keywords: rural revitalization; rural landscape resources; evaluation methods; probabilistic linguistics; Analytic Hierarchy Process (AHP); Cloud Model

\section{Introduction}

According to the Council of Europe Landscape Convention (CELC), a landscape is a perceived area characterized as the result of the action and interactions of natural and/or human factors. The landscape is an essential part of people's surroundings, an expression of the diversity of their shared cultural and natural heritage, a key element of the individual and social well-being, and the foundation of their identity [1]. It is also an important paradigm in sustainable development, with the aim of harmonious integration of social, economic, and environmental factors in space and time. Landscapes are being promoted at the global level by important institutions, such as UNESCO (United Nations Educational, Scientific and Cultural Organization) and the IUCN (International Union for Conservation of Nature), and through key regional directives and policies, such as the ELC (European Landscape Convention) and the CAP (Common Agricultural Policies) of Europe [2].

The rural landscape is usually defined as the landscape outside a town, consisting of natural landscape and agricultural production [3]. It includes a variety of geological and geographic features such as cropland, forests, deserts, swamps, grasslands, pastures, rivers, and lakes [4]. The rural landscape is not only the earliest landscape that appeared but also the most distributed one in the world [3]. After a long period of natural evolution and human management practices, environmental and social factors have interacted with each other and led to all kinds of complex rural landscapes [5].

The rural landscape provides natural resources and greenery to our living environment and maintains ecological equilibrium. It is also an important link between urban and rural areas, a possible cure for metropolitan health issues, and an essential source for tourism 
and rural modernization [6]. Therefore, rural landscapes play a key role in integrating human civilizations with natural environments and consolidating urban-rural relationships and prosperities [7-12].

The main content of the rural landscape is the rural agricultural landscape [13]. Since the 1950s, the intensification and expansion of modern agriculture have changed agricultural landscapes across Europe [14]. The CAP has impacted the evolution of European agricultural landscapes by driving changes in land use and farming practices [15]. According to the CAP, agri-environmental schemes focus on the maintenance and improvement of the agricultural landscape [16]. In some developing countries, rural revitalization is a strategy that promotes sustainable rural development and represents an inevitable trend toward global urbanization. The implementation of rural revitalization strategies is foundational to a modern economic system in developing countries. Rural revitalization requires that rural living environments should be improved, rural culture preserved, and rural industry promoted. It is crucial that the planning, design, development, transformation, and protection of the rural landscape follow the guidance of the rural revitalization strategy and policy and, more importantly, should be based on a comprehensive and accurate evaluation of landscape resources. Therefore, quantitative methods and results are indispensable in the study of the evaluation of rural landscape resources. Rural landscape resources are composed of the natural environment, agricultural activities, and natural, historical, and cultural factors of rural settlement in landscape form. (Rural landscape resources are composed of the natural environment, agricultural activities, historical and cultural factors of a rural settlement in landscape form). Their evaluation categories include the type, quality, structure, distribution, development, and utilization of landscape resources. Different scholars have evaluated the rural landscape resources from different perspectives, including experience evaluation [17], landscape features evaluation [18], aesthetic quality evaluation [19], visual aesthetic evaluation [20], visual quality evaluation [21], rural amenity resources [22], and so on. Various evaluation methods for rural landscape resources have been developed in the last few decades. These include single factor evaluation methods [23], fuzzy comprehension evaluation methods [24], AHP (Analytic Hierarchy Process) methods [25], and so on. Most evaluation methods focus on a single factor. For example, Wang and Deng (2016) constructed a comprehensive evaluation index of the rural landscape from the perspective of AVC (attraction, validity, and capacity) and evaluated a village in China [25]. Junge (2015) researched the influence of single agricultural landscape elements in different seasonal stages on landscape aesthetics, and the aesthetic preferences of Swiss residents for typical agricultural landscape elements in the Swiss lowlands were investigated by a photo survey [19]. Saronson (2007) identified landscape features in Indonesia and evaluated the environmental quality. It has been believed that the evaluation of landscape resources is usually affected by personal opinion, and there is a lack of quantitative processing of indicators when indicators are determined [18]. Panek (1997) analyzed agricultural landscape resources in the western region of Poland through climatic factor analysis and constructed appropriate landscape resources evaluation indicators [26].

At present, the evaluation of landscape resources in existing research focuses on the evaluation of tourism resources and visual aesthetics. There is a lack of research on the evaluation of the value of rural landscape resources from the perspective of rural revitalization.

Some of the previous methods can certainly be used to evaluate rural landscape resources; nevertheless, they usually neglect the uncertainties in the evaluation process and hence, cannot be transformed into effective and simple models. One of the solutions to this problem is to use the fuzzy sets theory, in which the uncertainty of the index system can be divided into fuzziness and randomness. As the main tool to tackle fuzzy problems, fuzzy sets theory portrays the uncertainty of fuzzy things by the degree of membership [27]. However, the concept of fuzzy is no longer fuzzy when it is introduced into the field of mathematics. About this problem, Li et al. propose a transition model of uncertainty between quality and quantity based on traditional fuzzy set theory and probability statistics: the Cloud Model [28]. They demonstrated that the knowledge 
representation and reasoning method of the Cloud Model could fully express the vagueness and randomness of uncertain knowledge and exhibits greater objectivity, which makes it possible to solve the problem of information loss in the process of information aggregation to a certain extent. The outstanding advantage of the Cloud Model lies in the randomness of membership and the inherent relationship between fuzziness and randomness, and it is an effective tool for dealing with the two [29]. Through the three mathematical characteristics of expectation, entropy, and hyper-entropy described by the Cloud Model, the conversion between qualitative and quantitative linguistics can be realized. After decades of research and development, the application of the Cloud Model has become increasingly extensive. The Cloud Model has many applications in various fields and has become a useful tool to deal with fuzziness and randomness. With the gradual maturity of cloud theory, more and more applications on Cloud Models emerge, such as online review analysis, energy assessment, supplier selection, plant siting, etc. The affiliation cloud enables the conversion between exact and value values by combining fuzziness and randomness. The value evaluation results can be expressed by the affiliation cloud to achieve a comprehensive evaluation of the effectiveness of rural landscape resources through uncertainty inference of the Cloud Model.

In this paper, we proposed a model based on the Cloud Model and the Probabilistic Linguistic Term Set (PLTS), which can solve the problem of the previous models in neglecting the evaluation of uncertainty. We then applied our model to a specific case-By analyzing the data sets provided by rural landscape resources of Xiapu Village in Guangdong, China, we evaluated the current rural landscape resources of Xiapu Village in specific areas, analyzed the evaluation results, and obtained an overall level for its rural landscape resources. Although this is an application of our model to a small village, it is not hard to generalize this model by incorporating more indicators and parameters to handle evaluation tasks with large scales and tackle more challenging evaluation questions. The quantitative results from the model can be considered important references that provide valuable suggestions for the further development, planning and design, transformation, and protection of the rural landscape at the practical level.

The rest of this paper is organized as follows: Section 2 illustrates the methodology of our model-building. Section 3 contains the results of applying our model to the case of Xiapu Village in Guangdong, China. Discussions are given in Section 4, and conclusions are drawn in Section 5.

\section{Methods}

\subsection{Cloud Model}

Cloud is an uncertainty transition model between some qualitative concepts and their quantitative expression in terms of the natural language value. In other words, the Cloud Model is an uncertainty model used to realize the transition between quality and quantity [30]. A Cloud is used to compare to an uncertainty mapping between quantity and quality. A Cloud can be formed by combining many Cloud drops, which individually may look insignificant, but the whole shape of the Cloud reflects the important characters of the quantity [31].

Assume that there is a set of evaluation attributes that are exactly represented on the quantitative universe $U$ and that there is a corresponding qualitative fuzzy concept. There is an arbitrary $(m=1,2 \ldots, \mathrm{n})$ corresponding membership degree in the universe $\mathrm{U}$, which is a stable random value and can reflect the certainty of attribute $x$. Then, the distribution of $x$ on $\mathrm{U}$ is a Cloud. The Cloud can be expressed as: $C=(E x, E n, H e)$ where each component of $C$ has the following meaning, respectively.

Expected value $E x$ is the expectation and represents the center value of the corresponding qualitative concept linguistic domain.

Entropy $E n$ is a measurement of the fuzziness of qualitative concepts, reflects the numerical range that can be accepted by this concept in the theory field, and embodies the uncertain margin of the qualitative concept. 
Hype Entropy He reflects the dispersion degree of cloud droplets and measures randomness. The bigger the Hyper Entropy is, the bigger of its dispersion and the randomness of the degree of membership, and so is the Cloud's thickness.

Therefore, the fuzziness (the uncertainty of qualitative concept) and randomness (randomness of the degree of membership) are completely combined together by three characteristic numbers of the Cloud Models, which make up the mapping between quality and quantity as the foundation of knowledge expression.

\subsection{Linguistic Scaling Function}

In the linguistic assessment scale, the semantic absolute deviation between any two adjacent linguistic terms may increase or decrease with an increase in linguistic subscripts. To reflect this situation, Bao et al. [32] introduced the linguistic scaling function (LSF).

Suppose there is a linguistic term $s_{i} \in S$ in which $S=\left\{s_{i} \mid i=1,2, \cdots, 2 t+1\right\}$. When $\theta_{i} \in[0,1]$ represents a value, $\mathrm{LSF}$ is defined from $s_{i}$ mapping to $\theta_{i}$ as follows:

$$
H: s_{i} \rightarrow \theta_{i}(i=1,2, \cdots, 2 t+1)
$$

LSF is a strictly monotonic function that is currently used in two linguistic-scaling functions as follows:

$$
\begin{aligned}
& L_{S S}=H_{1}\left(s_{i}\right)=\theta_{i}=\left\{\begin{array}{l}
\frac{a^{t}-a^{t-i+1}}{2 a^{t}-2}(i=1,2, \cdots, t+1) \\
\frac{a^{t}+a^{t-i-1}-2}{2 a^{t}-2}(i=t+2, t+3, \cdots, 2 t+1)
\end{array}\right. \\
& L_{S F}=H_{2}\left(s_{i}\right)=\theta_{i}=\left\{\begin{array}{l}
\frac{t^{\alpha}-(t-i+1)^{\alpha}}{2 t^{\beta}}(i=1,2, \cdots, t+1) \\
\frac{t^{\beta}+(i-t-1)^{\beta}}{2 t^{\beta}}(i=t+2, t+3, \cdots, 2 t+1)
\end{array}\right.
\end{aligned}
$$

The LSF1 is defined according to the exponential scale, taking different parameters $\alpha$, different types of exponential scales can be obtained. Through a large amount of experimental investigation data, $\alpha$ can be subjectively valued at 1.37 [32]. When the LSF2 is proposed based on prospect theory [33], the $\alpha$ and $\beta$ values can be 0.88 [34].

\subsection{Probabilistic Linguistic Term Sets}

Owing to the complexity of society, experts may feel comfortable using Linguistic Term Sets (LTSs), such as "good" and "poor", to express their opinions rather than crisp numbers. In many cases, experts are hesitant in the use of their words and may wish to use many linguistic terms to express their opinions. Especially for group decision-making processes, different experts may express many different opinions using many different terms for even one evaluation. For example, if there are three experts to evaluate a car, their opinions may range from "good" to "poor". Pang et al. proposed the definition of Probability Linguistic Term Sets (PLTS) [35].

Let $S=\left\{s_{1}, s_{2}, \cdots, s_{2 t+1}\right\}$ be a finite and completely ordered discrete linguistic term set with odd elements, then a probabilistic linguistic term set $T(p)$ is defined as follows:

$$
T(p)=\left\{t_{i}\left(p_{i}\right) \mid t_{i} \in S, 0 \leq p_{i} \leq 1, i=1,2, \cdots, \# t, \sum_{i=1}^{\# t} p_{i} \leq 1\right\}
$$

where $t_{i}\left(p_{i}\right)$ is a linguistic item associated with probability value $p_{i}$, and $\# t_{i}$ represents the number of elements in $T(p)$.

Based on the idea of prospect theory [36], a new preference value function is proposed for PLTS by considering the limited rationality of experts. For an evaluation value, different experts may make different subjective judgments due to their risk-preference attitudes. The preference value function is an effective way to convert the evaluation value into a preference value. 


\subsection{Evaluation Index Selection of Rural Landscape Resources}

In this study, the literature research and the Delphi methods were adopted based on the relevant literature and expert consultation. Finally, an evaluation system of rural landscape resources was established (see Table 1).

Table 1. Evaluation index system of rural landscape resources.

\begin{tabular}{|c|c|c|c|}
\hline $\begin{array}{l}\text { Evaluation } \\
\text { Target }\end{array}$ & $\begin{array}{l}\text { Evaluation } \\
\text { Dimension }\end{array}$ & Evaluation Index & Indicator Source \\
\hline \multirow{20}{*}{$\begin{array}{l}\text { Evaluation } \\
\text { index of rural } \\
\text { landscape } \\
\text { resources A }\end{array}$} & \multirow{6}{*}{$\begin{array}{l}\text { Environmental } \\
\text { value B1 }\end{array}$} & Landscape ecological value C1 & Yang, D. et al. (2014) [37] \\
\hline & & $\begin{array}{l}\text { Landscape environmental protection } \\
\text { degree } \mathrm{C} 2\end{array}$ & $\begin{array}{l}\text { Wang, J.L. et al. (2013) [38] Cai, Z.R. et al. } \\
\text { (2021) [39] }\end{array}$ \\
\hline & & Environmental cleanliness degree C3 & Liu, R. et al. (2021) [40] \\
\hline & & Environmental fusion degree $\mathrm{C} 4$ & (Obtained from CELC and expert consultations) \\
\hline & & Geographical location value C5 & Kristensen, S.B.P. et al. (2016) [41] \\
\hline & & Rural livability C6 & Dissanayake, D. et al. (2018) [42] \\
\hline & \multirow{5}{*}{ Social value B2 } & Attribution value C7 & Ian, C.M. et al. (2013) [43] \\
\hline & & Historical heritage value $\mathrm{C} 8$ & $\begin{array}{l}\text { Tengberg A. et al. (2012) [44] Dupont, L. et al. } \\
\text { (2013) [45] }\end{array}$ \\
\hline & & Educational memorial value C9 & $\begin{array}{l}\text { Irina-Maria, N. et al. (2015) [46] Enslin, P., } \\
\text { (2020) [47] }\end{array}$ \\
\hline & & Social popularity $\mathrm{C} 10$ & Prakash, K., (2016) [48] \\
\hline & & Cultural value C11 & Janet, S., (2007) [49] Koen, F. et al. (2017) [50] \\
\hline & \multirow{3}{*}{ Economic value B3 } & Agricultural production value $\mathrm{C} 12$ & Mara, T. et al. (2013) [51] \\
\hline & & Rural tourism value C13 & Kaswanto (2015) [52] \\
\hline & & Sustainable development value C14 & Cerreta, M. et al. (2014) [53] \\
\hline & \multirow{6}{*}{$\begin{array}{l}\text { Landscape } \\
\text { value B4 }\end{array}$} & Landscape type richness C15 & Oehri, J. et al. (2020) [54] \\
\hline & & Landscape quantity richness C16 & (Obtained from CELC and expert consultations) \\
\hline & & Landscape uniqueness C17 & $\begin{array}{l}\text { Zelinsky, W., (2001) [55], Asrina, M. et al. } \\
\text { (2017) [56] }\end{array}$ \\
\hline & & Landscape integrity C18 & $\begin{array}{l}\text { Walston, L.J. et al. (2018) [57] Rasouli, S. et al. } \\
\text { (2012) [58] }\end{array}$ \\
\hline & & Landscape artistic value C19 & Chen, Y. et al. (2016) [59] \\
\hline & & Landscape aesthetic value C20 & $\begin{array}{l}\text { Yang, D. et al. (2014) [37] Tribot, A.S. et al. } \\
\text { (2018) [60] }\end{array}$ \\
\hline
\end{tabular}

We set up a 3-layer index. The first layer is the evaluation target, the second layer is the evaluation dimension, and the third layer is the evaluation factor.

The second layer includes the following indicators: environmental value B1, social value $\mathrm{B} 2$, economic value $\mathrm{B}$, and landscape value $\mathrm{B} 4$. The third layer includes 20 indicators $\mathrm{C} 1, \mathrm{C} 2 \ldots \mathrm{C} 20$, such as landscape ecological value, attribution value, rural production value, and landscape type richness.

These evaluation indicators are all 5 levels. The score of each question ranges from 1 to 5 . The meanings of different scores are as follows: 1 is "very poor", 2 is "poor", 3 is "fair", 4 is "good", and 5 is "very good".

\subsection{Construction of the Rural Landscape Resources Value Evaluation Model}

The Analytic Hierarchy Process (AHP) is a simple method for analyzing non-quantitative events using quantitative analysis, which is very effective in systems analysis and scientific decision-making. Landscape resources are complex and have multiple value attributes, and 
different factors have varying levels of importance. Concurrently, in the existing evaluation system research, AHP is the most commonly used method, which is consistent with the purpose of this study; therefore, this study intends to use AHP to determine the weight of rural landscape resources value evaluation index.

The former evaluation models include factor analysis, fuzzy comprehensive evaluation, and the entropy weight method. Because the evaluation index established in this study is difficult to quantify, the evaluation object itself is fuzzy, the content is complex, and it has the characteristics of a multi-layer structure. Moreover, the subjectivity of expert knowledge must be considered as well as the potential inadequate mastery of known information; therefore, this paper introduces the Probabilistic Linguistic Term Set (PLTS), which can not only comprehensively depict the evaluation preference of decision-makers but also quantify the preference degree so that the decision results are more reliable and practical. In addition, the existing research on PLTSs inevitably involves the loss and distortion of probabilistic linguistic information [61]; thus, existing methods cannot effectively deal with the decision information of PLTSs. Therefore, this study introduces a probabilistic linguistic cloud to address decision-making problems.

Based on the theory of AHP and the probabilistic linguistic Cloud Model, we now build a comprehensive evaluation system of the AHP-probabilistic linguistic Cloud Model. The specific steps for constructing this model are detailed as follows.

Step 1: Expert comment conversion into probabilistic linguistic information

Assuming that there are $n$ evaluation indexes to form a set $C=\left\{c_{1}, c_{2}, \ldots, c_{n}\right\}$, the expert scoring set under the index is determined as $S=\left\{s_{1}, s_{2}, \ldots, s_{m}\right\}$. Assuming that there are $\mathrm{K}$ experts $V=\left\{v_{1}, v_{2}, \ldots, v_{k}\right\}$, the probability linguistic evaluation matrix of expert evaluations can be obtained using the comment set $S$ to evaluate $n$ evaluation indexes $H=\left(h_{i}\right)_{m \times n}=\left(t_{i}\left(p_{i}\right)\right)_{m \times n}=\left(\underline{H e}_{i}, \underline{E n_{i}}, E x_{i}, \overline{E n_{i}}, \overline{H e_{i}}\right)$. According to the evaluation system, the Cloud Model interval is divided into $[0,10]$, and the corresponding domain is $\left[X_{\min }, X_{\max }\right]$.

(1) Calculate the value of linguistic terms $\theta$ according to the linguistic scale function. According to the experimental results of Chen et al. [34], different LSFs do not affect the final experimental results; to facilitate the calculation, LSF1 is selected as the linguistic scale function.

(2) Calculate $E x_{i}, E x_{i}=X \min +\theta_{i}(X \max -X \min )$;

(3) Calculate $E n_{i}$ and $\overline{E n_{i}}$,

$$
E n_{1}=0, \underline{E n_{i}}=\left(E x_{i}-E x_{i-1}\right) / 3, \overline{E n_{2 t+1}}=0, \overline{E n_{i}}=\left(E x_{i+1}-E x_{i}\right) / 3 \text {; }
$$

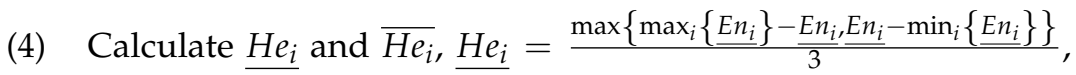

$$
\overline{H e_{i}}=\frac{\max \left\{\max _{i}\left\{\overline{E n_{i}}\right\}-\overline{E n_{i}} \overline{E n_{i}}-\min _{i}\left\{\overline{E n_{i}}\right\}\right\}}{3} ;
$$

Step 2: Probabilistic linguistic cloud $\mathrm{Z}$ design

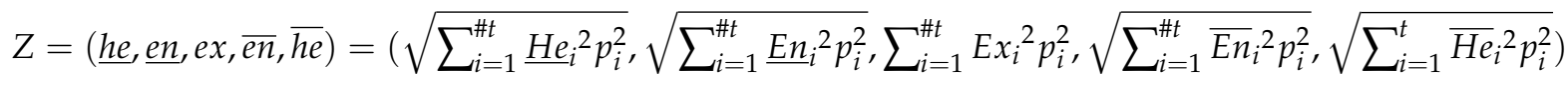

Step 3: Determining index weight

Obtain the expert's accurate scoring value for each level of the rural landscape resources evaluation index system. According to the AHP, calculating the corresponding index weight vector $W=\left(w_{1}, w_{2}, \ldots \ldots, w_{i}\right)$ and $w_{i} \in[0,1], w_{1}+w_{2}+\ldots+w_{i}=1$.

Step 4: Comprehensive evaluation information calculation

(1) According to the index weight obtained in Step 3, the probabilistic linguistic cloud for each factor $\mathrm{C}$ can be calculated. The relevant operation rules of the probabilistic linguistic cloud are as follows: 


$$
\begin{gathered}
Z_{i}+Z_{j}=\left(\sqrt{\underline{h e}_{i}+\underline{h e}_{j}}, \sqrt{\underline{\underline{e n}}_{i}+\underline{e n}_{j}}, e x_{i}+e x_{j}, \sqrt{\overline{e n_{i}}+\overline{e n_{j}}}, \sqrt{\overline{h e_{i}}+\overline{h e_{i}}}\right) \\
\lambda Z_{i}=\left(\sqrt{\lambda} \underline{h e}_{i}, \sqrt{\lambda} \underline{\underline{e n}}_{i}, \lambda e x_{i}, \sqrt{\lambda} \overline{e n}_{i}, \sqrt{\lambda h e_{i}}\right)
\end{gathered}
$$

(2) According to the Probabilistic Linguistic Integrated Cloud Weighted Heronian Mean (PLICWHM) operator, the comprehensive evaluation information under each factor is obtained. The calculation formula for PLICWHM is as follows:

$$
\begin{aligned}
& \operatorname{PLICWM}\left(z_{1}, z_{2}, \cdots z_{q}\right)=\sum w_{i} z_{i} \\
& \left.=\left(\sqrt{\sum_{i=1}^{q}\left(w_{i} \underline{h e_{i}}\right)^{2}}, \sqrt{\sum_{i=1}^{q}\left(w_{i} \underline{e n} \underline{n}_{i}\right.}\right)^{2}, \sum_{i=1}^{q} w_{i} e x_{i}, \sqrt{\sum_{i=1}^{q}\left(w_{i} \overline{e n}_{i}\right)^{2}}, \sqrt{\sum_{i=1}^{q}\left(w_{i} \overline{h e}_{i}\right)^{2}}\right)
\end{aligned}
$$

Here, $q$ is the number of indicators at this level, and $w_{i}$ is the weight of these indicators. Step 5: Similarity comparison

The comprehensive Cloud Model and the model of each attribute in the standard cloud are compared to obtain a standard evaluation cloud that is the most similar. The qualitative evaluation corresponding to the evaluation cloud is the result of computing this index factor. The distance measure formula is as follows:

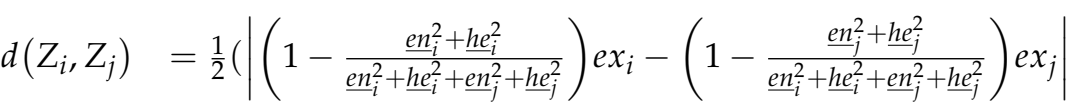

$$
\begin{aligned}
& \left.+\left|\left(1-\frac{\overline{e n}_{i}^{2}+\overline{h e}_{i}^{2}}{\overline{e n}_{i}^{2}+\overline{h e}_{i}^{2}+\overline{e n}_{j}^{2}+\overline{h e}_{j}^{2}}\right) e x_{i}-\left(1-\frac{\overline{e n}_{j}^{2}+\overline{h e}_{j}^{2}}{\overline{e n}_{i}^{2}+\overline{h e}_{i}^{2}+\overline{e n}_{j}^{2}+\overline{h e}_{j}^{2}}\right) e x_{j}\right|\right)
\end{aligned}
$$

If $\left(a_{t}=b_{t}=0\right)\left(a_{t}=\underline{e n_{t}}, \overline{e n}_{t} ; b_{t}=h e_{t}, \overline{h e}_{t} ; t=i, j\right)$, then $\frac{a_{i}^{2}+b_{i}^{2}}{a_{i}^{2}+b_{i}^{2}+a_{j}^{2}+b_{j}^{2}}=0$ and $\frac{a_{j}^{2}+b_{j}^{2}}{a_{i}^{2}+b_{i}^{2}+a_{j}^{2}+b_{j}^{2}}=0$.

To demonstrate our method and verify the model, we will take an example, which is the evaluation of rural landscape resources in a village in Guangdong (Xiapu Village), China, in the next section (Section 3). A detailed analysis will be given there, and the values of evaluation parameters will be determined. The original data sets are available on the authors' website.

Duozhu Town is a tourist-oriented town featuring the development of rural tourism and ecological agriculture in Guangdong Province, China. It is also the gateway to the northern mountainous region of Huidong County and a distribution base for agricultural and trade products. The object of our study is Xiapu Village, which is located in Duozhu Town (Figure 1). The overall topography of the study area is characterized by gentle slopes with a maximum height difference of approximately $240 \mathrm{~m}$. The plain is predominant and interspersed with small hills and hollows. The village is one of the areas where Hakka dwellings are concentrated [62-64].

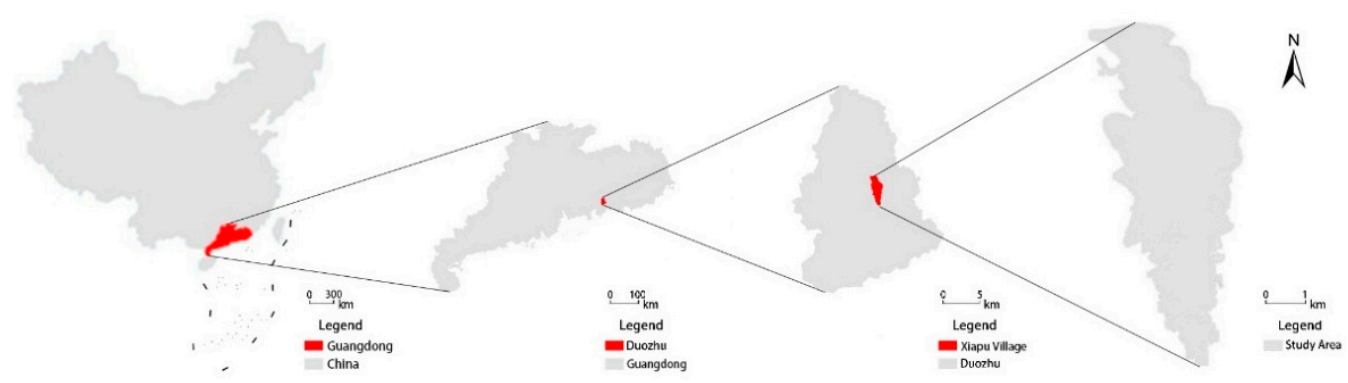

Figure 1. The location of the study area.

In this study, the authors made a field investigation of Xiapu Village, took a lot of pictures, and conducted interviews. On this basis, a questionnaire has been designed (see 
Appendix A). The authors also invited professors and doctoral students from Central South University of Forestry and Technology (three people), Sichuan Agricultural University (two people) and Hunan University (two people), experts from landscape planning and design companies (two people), and a manager from Changsha Garden Bureau (one person, 10 people in total) for answering the questionnaire and other consultations related to the model-building.

The steps for evaluating the value of rural landscape resources are as follows.

(1) According to the evaluation index system of rural landscape resources, the index set is determined as $C=\left\{c_{1}, c_{2}, \ldots, c_{n}\right\}$, and the comment set $S=\left\{s_{1}, s_{2}, s_{3}, s_{4}, s_{5}\right\}$ represents very poor, poor, general, good, and very good, respectively. The universe of discourse in the Cloud Model was $[0,10]$. The scale of the cloud evaluation was calculated accordingly (Table 2).

Table 2. Linguistic term cloud digital features.

\begin{tabular}{lccccc}
\hline \multicolumn{1}{c}{ Linguistic Terms } & $\underline{\boldsymbol{E n}}$ & $\underline{\boldsymbol{H e}}$ & $\boldsymbol{E x}$ & $\overline{\boldsymbol{E n}}$ & $\overline{\boldsymbol{H e}}$ \\
\hline$S_{1}$ Very poor & 0 & 0 & 0 & 0.96 & -0.32 \\
$S_{2}$ Poor & 0.09 & 0.96 & 2.89 & 0.70 & 0 \\
$S_{3}$ General & 0 & 0.70 & 5 & 0.70 & -0.09 \\
$S_{4}$ Good & 0 & 0.70 & 7.11 & 0.96 & -0.09 \\
$S_{5}$ Very good & 0.09 & 0.96 & 10 & 0 & 0 \\
\hline
\end{tabular}

(2) Determining index weight The comprehensive data obtained from the investigation in the region were sent to the experts together with the questionnaire, and the weight was scored according to the index system of rural landscape resources. AHP is a 2-to-2 comparison method to determine the relative importance of each factor in the hierarchy and then integrates the expert's judgment to determine the overall ranking. Therefore, in this paper, AHP takes a 1-9 scale, that is, 1, 3, 5, 7, and 9 representing a factor compared with another factor that is equally important, slightly important, more important, very important, absolutely important; 2, 4, 6, and 8 representing the median of the above two adjacent judgments, and the inverse comparison of the two factors is expressed by the reciprocal. In this study, the final expert scoring data weighted average was determined, a pairwise comparison judgment matrix was constructed, and the weight value of each index was subsequently calculated. The results are shown in Table 3.

In Table 3, weights are given for each evaluation indicator.

(3) Cloud construction According to the index and comment sets, 10 experts were selected to evaluate the case village according to the evaluation index system of rural landscape resources to obtain the initial evaluation data. Taking the evaluation information given by the experts under the secondary indicators of social value $B 2(C 7, C 8, C 9$, $\mathrm{C} 10, \mathrm{C} 11)$ as an example, the calculation process is described below. The evaluation information is listed in Table 4.

In Table 4, the probability that the C7 indicator belongs to the S3 level is $9 \%$, and the probability of the C7 indicator belonging to the $\mathrm{S} 2$ level is $10 \%$. (Of the ten respondents, nine are considered to belong to S3 and 1 to S2.) 
Table 3. Evaluation index weight table.

\begin{tabular}{|c|c|c|c|}
\hline $\begin{array}{l}\text { Evaluation } \\
\text { Dimension }\end{array}$ & Weights & Evaluation Factor & Weights \\
\hline \multirow{6}{*}{$\begin{array}{c}\text { Environmental } \\
\text { value }\end{array}$} & \multirow{6}{*}{0.14} & Landscape ecological value & 0.1286 \\
\hline & & Landscape environmental protection degree & 0.1 \\
\hline & & Environmental cleanliness degree & 0.1571 \\
\hline & & Environmental fusion degree & 0.1929 \\
\hline & & Geographical location value & 0.1214 \\
\hline & & Rural Livability & 0.3 \\
\hline \multirow{5}{*}{ Social value } & \multirow{5}{*}{0.19} & Attribution value & 0.2789 \\
\hline & & Historical heritage value & 0.1526 \\
\hline & & Educational memorial value & 0.0895 \\
\hline & & Social popularity & 0.2105 \\
\hline & & Cultural Value & 0.2684 \\
\hline \multirow{3}{*}{ Economic Value } & \multirow{3}{*}{0.24} & Agricultural production value & 0.2917 \\
\hline & & Rural tourism value & 0.4708 \\
\hline & & Sustainable development value & 0.2417 \\
\hline \multirow{6}{*}{ Landscape value } & \multirow{6}{*}{0.43} & Landscape type richness & 0.2395 \\
\hline & & Landscape quantity richness & 0.1791 \\
\hline & & Landscape uniqueness & 0.0907 \\
\hline & & Landscape integrity & 0.1395 \\
\hline & & Landscape artistic value & 0.0791 \\
\hline & & Landscape aesthetic value & 0.2698 \\
\hline
\end{tabular}

Table 4. Probabilistic linguistic information from the expert evaluation under social value indicator B2.

\begin{tabular}{llllll}
\hline & S1 & S2 & S3 & S4 & S5 \\
\hline C7 & & 0.1 & 0.9 & & \\
C8 & 0.3 & 0.6 & 0.1 & & \\
C9 & 0.1 & 0.8 & 0.1 & & \\
C10 & & 0.1 & 0.8 & 0.1 & \\
C11 & & 0.2 & 0.6 & 0.2 & \\
\hline
\end{tabular}

The expert evaluation information (Table 4) was converted into a probabilistic linguistic Cloud Model according to the conversion formula between probabilistic linguistic and PLIC as well as the linguistic term cloud digital feature of Table 2, and the results are shown in Table 5. Similarly, the probability linguistic Cloud Model corresponding to each indicator can be obtained, and the calculation results are listed in Table 6.

Table 5 is a probabilistic language Cloud Model converted from Table 4.

The calculations in Table 6 are similar to those in Table 5.

The probabilistic linguistic cloud parameters of each project evaluation layer B can be calculated according to the PLICWHM operator of the probabilistic linguistic cloud calculation formula (Table 7).

Table 5. Expert evaluation of secondary indicators under social value indicator B2.

\begin{tabular}{cccccc}
\hline Index C & $\underline{\boldsymbol{E n}}$ & $\underline{\boldsymbol{H} \boldsymbol{e}}$ & $\boldsymbol{E x}$ & $\overline{\boldsymbol{E n}}$ & $\overline{\boldsymbol{H e}}$ \\
\hline C7 & 0.0114 & 0.1269 & 0.3877 & 0.1226 & 0.0266 \\
C8 & 0.0115 & 0.1300 & 0.4166 & 0.0963 & 0.0032 \\
C9 & 0.0017 & 0.0784 & 0.5444 & 0.0774 & 0.0094 \\
C10 & 0.0003 & 0.1015 & 0.8030 & 0.1114 & 0.0125 \\
C11 & 0.0159 & 0.1782 & 0.5582 & 0.1313 & 0.0027 \\
\hline
\end{tabular}


Table 6. Probabilistic linguistic cloud of each evaluation index.

\begin{tabular}{cccccc}
\hline Index C & $\underline{\boldsymbol{E n}}$ & $\underline{\boldsymbol{H} \boldsymbol{e}}$ & $\boldsymbol{E x}$ & $\overline{\boldsymbol{E n}}$ & $\overline{\boldsymbol{H e}}$ \\
\hline C1 & 0.0031 & 0.0594 & 0.3641 & 0.0552 & 0.0082 \\
C2 & 0.0015 & 0.0546 & 0.5203 & 0.0669 & 0.0064 \\
C3 & 0.0021 & 0.0739 & 0.5229 & 0.0745 & 0.0086 \\
C4 & 0.0022 & 0.0240 & 0.1401 & 0.1162 & 0.0383 \\
C5 & 0.0034 & 0.0673 & 0.4176 & 0.0628 & 0.0069 \\
C6 & 0.0020 & 0.1301 & 0.9143 & 0.1293 & 0.0158 \\
C7 & 0.0114 & 0.1269 & 0.3877 & 0.1226 & 0.0266 \\
C8 & 0.0115 & 0.1300 & 0.4166 & 0.0963 & 0.0032 \\
C9 & 0.0017 & 0.0784 & 0.5444 & 0.0774 & 0.0094 \\
C10 & 0.0003 & 0.1015 & 0.8030 & 0.1114 & 0.0125 \\
C11 & 0.0159 & 0.1782 & 0.5582 & 0.1313 & 0.0027 \\
C12 & 0.0078 & 0.1268 & 1.2732 & 0.1229 & 0.0114 \\
C13 & 0.0165 & 0.1859 & 0.5884 & 0.1700 & 0.0337 \\
C14 & 0.0090 & 0.1262 & 0.6444 & 0.1082 & 0.0095 \\
C15 & 0.0242 & 0.2706 & 0.8335 & 0.1986 & 0.0036 \\
C16 & 0.0137 & 0.1739 & 0.7520 & 0.1393 & 0.0104 \\
C17 & 0.0000 & 0.1137 & 1.1299 & 0.1533 & 0.0140 \\
C18 & 0.0027 & 0.1531 & 1.5492 & 0.2055 & 0.0185 \\
C19 & 0.0115 & 0.1305 & 0.4552 & 0.0991 & 0.0032 \\
C20 & 0.0123 & 0.1827 & 1.8688 & 0.1640 & 0.0149 \\
\hline
\end{tabular}

Table 7. Probabilistic linguistic cloud parameters of each project evaluation layer.

\begin{tabular}{cccccc}
\hline Index C & $\underline{\boldsymbol{E n}}$ & $\underline{\boldsymbol{H e}}$ & $\boldsymbol{E x}$ & $\overline{\boldsymbol{E n}}$ & $\overline{\boldsymbol{H e}}$ \\
\hline B1 & 0.0060 & 0.1844 & 1.3064 & 0.2173 & 0.0441 \\
B2 & 0.0228 & 0.2849 & 1.2556 & 0.2448 & 0.0312 \\
B3 & 0.0204 & 0.2580 & 1.5435 & 0.2360 & 0.0368 \\
B4 & 0.0326 & 0.4361 & 2.9388 & 0.4016 & 0.0298 \\
\hline
\end{tabular}

(4) Similarity comparison The distance between the Cloud Model and standard linguistic set under each index can be obtained using the distance measure formula. The calculation results are shown in Table 8, where the shortest distances are represented in bold font.

The final cloud parameters of target layer A are $(0.0778,0.4269,10.434,0.0461,0.21)$.

Table 8. Distance measurement between the cloud and the standard linguistic set under each index.

\begin{tabular}{|c|c|c|c|c|c|}
\hline & S1 & S2 & S3 & S4 & S5 \\
\hline $\mathrm{C} 1$ & 0.2032 & 1.6002 & 2.6520 & 3.7038 & 5.1445 \\
\hline $\mathrm{C} 2$ & 0.5175 & 0.4997 & 0.4866 & 0.4736 & 0.4558 \\
\hline C3 & 0.5171 & 0.4850 & 0.4616 & 0.4382 & 0.4061 \\
\hline C4 & 0.1379 & 0.1133 & 0.0953 & 0.0774 & 0.0712 \\
\hline $\mathrm{C} 5$ & 0.2366 & 1.6746 & 2.7245 & 3.7744 & 5.2123 \\
\hline C6 & 0.4507 & 1.8722 & 2.9100 & 3.9478 & 5.3692 \\
\hline $\mathrm{C} 7$ & 0.3783 & 0.3085 & 0.2576 & 0.2066 & 0.1368 \\
\hline $\mathrm{C} 8$ & 0.4058 & 0.3308 & 0.2761 & 0.2213 & 0.1463 \\
\hline C9 & 0.5393 & 0.5120 & 0.4920 & 0.4721 & 0.4448 \\
\hline C10 & 0.4685 & 1.7530 & 2.7964 & 3.8398 & 5.2690 \\
\hline C11 & 0.3992 & 1.5629 & 2.6004 & 3.6379 & 5.0590 \\
\hline $\mathrm{C} 12$ & 1.2426 & 1.1744 & 1.1246 & 1.0748 & 1.0065 \\
\hline C13 & 0.5522 & 0.3741 & 0.2441 & 0.1141 & 0.0640 \\
\hline C14 & 0.6314 & 0.5676 & 0.5210 & 0.4744 & 0.4106 \\
\hline C15 & 0.7632 & 2.1020 & 3.0794 & 4.0568 & 5.3955 \\
\hline C16 & 0.4999 & 1.6481 & 2.6834 & 3.7187 & 5.1367 \\
\hline C17 & 1.1015 & 1.0150 & 0.9519 & 0.8887 & 0.8023 \\
\hline C18 & 1.4514 & 1.2716 & 1.1404 & 1.0091 & 0.8294 \\
\hline C19 & 0.4466 & 0.3826 & 0.3359 & 0.2891 & 0.2251 \\
\hline $\mathrm{C} 20$ & 1.1291 & 2.5237 & 3.5420 & 4.5603 & 5.9550 \\
\hline B1 & 1.1689 & 1.2084 & 1.1527 & 0.8222 & 1.1817 \\
\hline B2 & 0.5928 & 0.8618 & 0.4738 & 0.4069 & 5.1757 \\
\hline B3 & 1.1661 & 0.7313 & 0.8194 & 0.7214 & 5.3860 \\
\hline B4 & 1.4683 & 2.0854 & 1.1915 & 0.9872 & 3.9100 \\
\hline A & 5.3709 & 0.7623 & 0.4559 & 0.3561 & 0.9053 \\
\hline
\end{tabular}




\section{Results}

According to the results in Table 8, for the evaluation of the rural landscape resources in Xiapu Village, index A belongs to S4 (good) because the distances between the A indicator and S1, S2, S3, S4, and S5 are 5.37, 0.76, 0.46, 0.35, and 0.91, respectively, and the distance from $\mathrm{S} 4$ is the closest, so it belongs to $\mathrm{S} 4$.

The second-level indicators B1, B2, B3 and B4 all belong to S4 (good), indicating that the overall levels of the rural landscape resources in Xiapu Village are "good", but there is still much room for improvement as the values of certain indicators suggest. The relevant information (associated with the indicators of our model) is given below for comparison purposes.

According to Table 7, we can draw the cloud models of B1, B2, B3 and B4 (Figure 2).

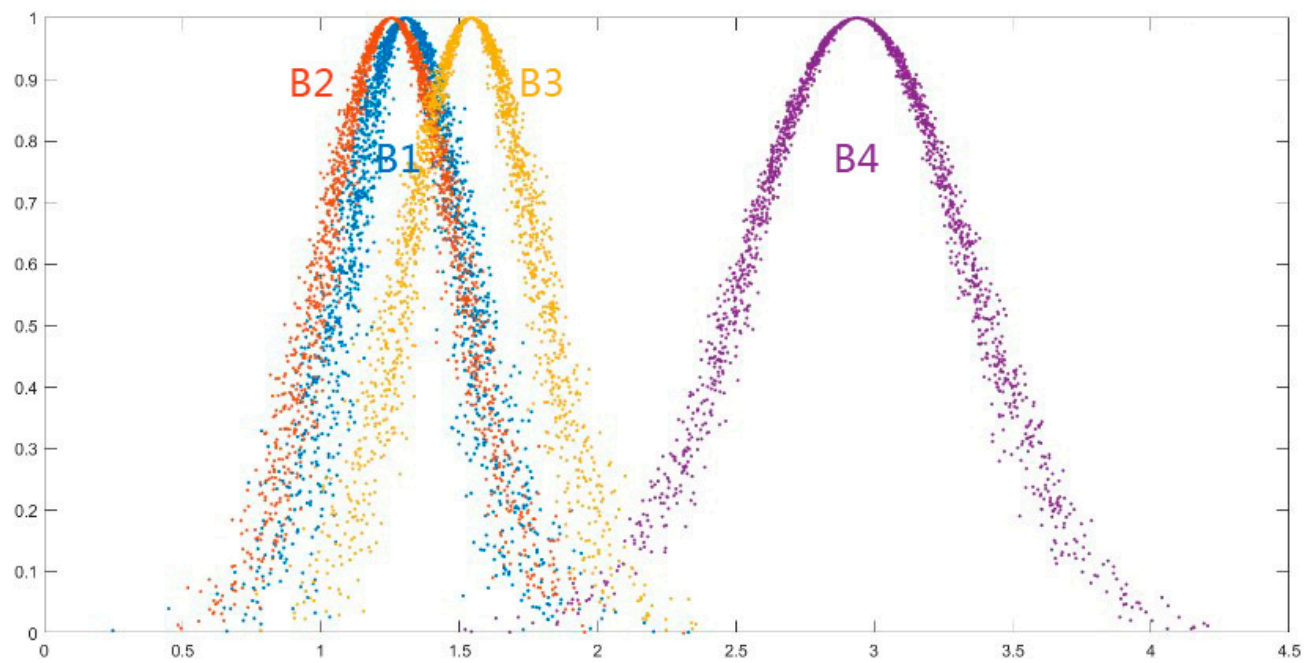

Figure 2. Cloud image of B1-B4. Note: The $X$-axis represents En (entropy); On the $Y$-axis is Ex. In the tertiary indicators (B1), C2, C3, and C4 belong to S4 (good), C1, C6 to S1 (very poor), but because the sum of $\mathrm{C} 1$ and $\mathrm{C} 15$ is small, the sum of $\mathrm{C} 2, \mathrm{C} 3$, and $\mathrm{C} 4$ is large, so the environmental value (B1) is "good".

\section{Discussions}

To check whether our model yields reliable results, we have retrieved more information about the landscape resources of Xiapu Village (see [62-64]), which is independent of our field investigation. From [62-64], the original vegetation of Xiapu Village is well protected, the overall environment is clean, and the integration of the architectures and the natural environment is good. Therefore, the degree of landscape environmental protection (C2), environmental cleanliness degree (C3), and environmental fusion degree (C4) is "good". However, the original mountains and water bodies had not been moderately developed under the premise of protection and did not play the potential value of landscape and economy. The number of vegetation species is also relatively small, and part of the water ecosystem was damaged due to construction. The village is far away from other cities, and the transportation is inconvenient for tourists. The village has some unused land, while the public green spaces and the venues and facilities for public activities are insufficient. Therefore, these are consistent with the result that the landscape ecological value (C1), geographical location value (C5), rural livability (C6) is "very poor".

In the tertiary indicators (B2), C8, and C9 belong to S5 (very good), C7 to S4 (good), $\mathrm{C} 10$ and $\mathrm{C} 11$ to $\mathrm{S} 1$ (very poor) because the weighted sum of $\mathrm{C} 7, \mathrm{C} 8, \mathrm{C} 9$ is large and the sum of C10 and C11 is small, so the social value (B2) is "good". From [62-64], Xiapu Village has kept traditional Chinese architecture, such as ancestral halls, Buddhist temples, Taoist temples, and courtyard folk houses. The protection and inheritance of traditional folk culture are good, and the self-identification of local residents is strong. Therefore, these are consistent with the result that the historical heritage value (C8) and the educational 
memorial value (C9) are both "very good", and the attribution value (C7) is "good". However, some of the traditional architecture was damaged and lost its original features and styles due to the lack of proper maintenance. The public activities of the village have been restricted to the most basic ones, such as the traditional gathering places, such as the aforementioned ancestral halls, Buddhist temples, and Taoist temples, which are too small for the villagers to carry out social and cultural activities such as ancestor-worshipping and festival-celebrating, not to mention that the historical and cultural characteristics of the village should be used to attract tourists. Thus, these are consistent with the result that the social popularity (C10) and the cultural value (C11) are "poor".

In the three-level indicators $\mathrm{B} 3$, all indicators $\mathrm{C} 12, \mathrm{C} 13$, and $\mathrm{C} 14$ belong to $\mathrm{S} 5$ (very good), so the economic value (B3) is "good". From [62-64], Xiapu Village is located mainly in a plain with plenty of water resources and some mountains adjacent to its north side, suitable for the development of rural tourism. The village also has many agricultural economic types that are supported by the local government, especially in the ecological agricultural industry. Therefore, these support the result that the agricultural production value $(\mathrm{C} 12)$, the rural tourism value $(\mathrm{C} 13)$, and the sustainable development value (C14) are "very good".

In the tertiary indicators (B4), C17, C18, C19 belong to S5 (very good), C15, C16, and $\mathrm{C} 20$ belong to $\mathrm{S} 1$ (very poor) because the sum of $\mathrm{C} 15, \mathrm{C} 16$, and $\mathrm{C} 20$ is small, $\mathrm{C} 17, \mathrm{C} 18$, C19 are large, so the landscape value (B4) is "good". With a memorial monument for soldiers and a few Hakka stores, the village has a distinctive architectural style. Besides the traditional folk activities, the villagers also spontaneously decorated the walls of their houses with paintings, adding certain artistic quality to the landscape. For comparison, the landscape uniqueness (C17), the landscape integrity (C18), and the landscape artistic value (C19) are "very good". The types of landscapes are quite limited, and most of them are temples and ancestral halls that need renovations. These are comparable with our result that landscape type richness, quantitative abundance, and landscape aesthetic value (C20) are "poor".

Specifically, we can see from Figure 3, the values of the indices C1, C5, C6, C10, C11, $\mathrm{C} 15, \mathrm{C} 16, \mathrm{C} 20$ all belong to level S1, very low, shows that these aspects should be improved.

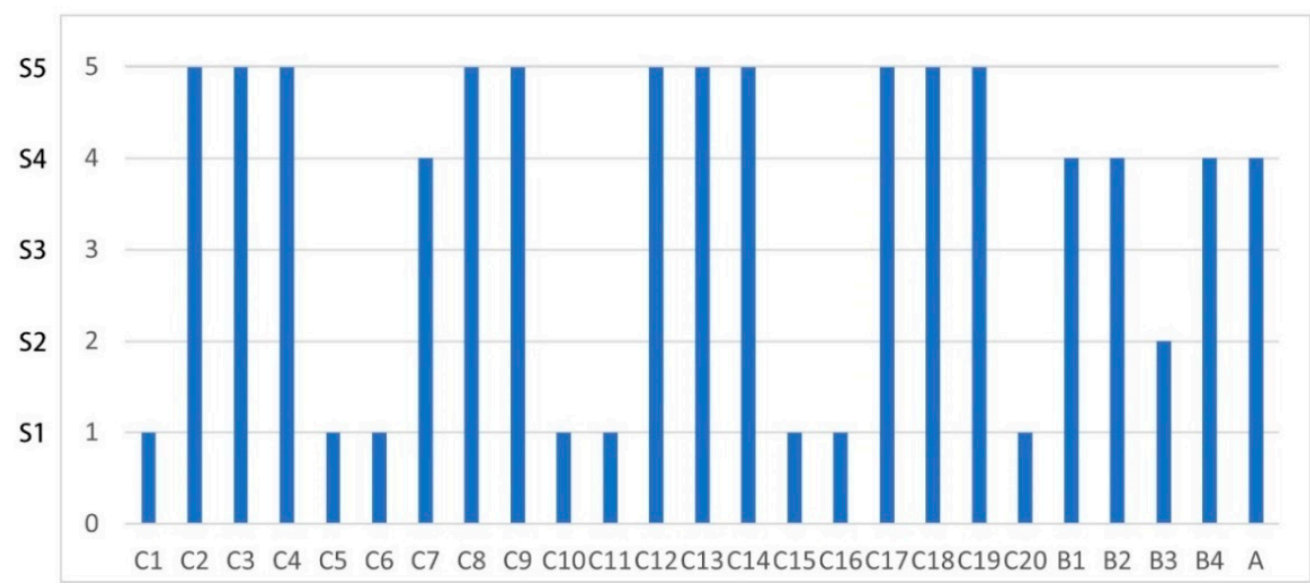

Figure 3. The evaluation levels of the indices.

\section{Conclusions and Suggestions}

In this article, we proposed a new approach for evaluating rural landscape resources. We have established a new index system by using the Analytic Hierarchy Process (AHP) and a probabilistic linguistic Cloud Model. We explained the details of building such an index system and applied our method to the case study of Xiapu Village. The evaluation results and the item-by-item analysis in the last section show that the method is practical and can reflect the value of resources objectively and efficiently. 
We evaluate the landscape resources of Xiapu Village, and the overall evaluation level is "good" because most of the indicators have higher scores. Our method also found the weakness and inadequacy of its landscape resources. Moreover, one can use the indicators and their values as guidance for achieving a higher evaluation score and, hence, better management of the landscape resources. Based on our method and the case study of Xiapu Village, we can make suggestions for improvements on the following aspects:

(1) Suggestions for improving the environmental value (B1). Rural livability is critical to the B1 value. In some developing countries and regions, the lack of rural environmental protection and planning has resulted in land exposure, soil erosion, and destruction of the original vegetation. Landscape architects can improve the ecological environment and use natural self-purification functions to keep the environment clean, enabling the landscape to maintain its ecological value. The landscape architect can also design ecological revetments and plant aquatic vegetation, which can improve the purification capacity of water. Landscape architects can further enrich the vegetation types of villages and grow plants near the dwellings, which protect the ecosystem and make the countryside more livable. Last but not least, transportations to other places should be made easy and convenient to increase rural livability. Reference [25] believes that convenient transportation conditions and a clean village appearance are conducive to the development of rural tourism advantages. In this respect, our conclusions are consistent with the ref. [25].

(2) Suggestions to improve the social value (B2). The cultural value (C11) and the attribution value (C7) are very important in B2. Public places such as historical halls, cultural exhibition centers, theaters, and museums can be used to display the local history and culture, the traditional rural customs, such as local folk customs and religions, art and music, legends and anecdotes, and other historical and cultural heritage so that tourists might feel a rich cultural atmosphere with diversity, which certainly increases the cultural value. Landscape designs should be conducted based on the existing infrastructure and the needs of the residents for more social activities. With a more pleasant and convenient living environment and more space and opportunities for social activities, the local residents may choose to stay in their hometown for work, and the attribution value (C7) can be improved as well. In the study of approximate themes, Čurović Ž. et al. suggested preserving the architectural identity with the planned development and renewal of settlements is implemented through landscape [65]. We reached conclusions similar to those of the ref. [65].

(3) Suggestions for increasing economic value (B3). The rural tourism value (C13) is the major value in B3. When landscape architects consider the rural landscape as a tourist attraction, they should make sure that the normal agricultural production activities are undisturbed through planning and design. For example, the farmland for tourists' experience should be separated from those for daily production. Alternatively, air trails over the farmland can be built for tourist visits. Other approaches can be taken to increase the richness of landscape types. Landscape architects can improve tourism infrastructure and service facilities, such as information centers, parking lots, comfort stations, and medical stations. Different rural landscape areas, such as an ecological agricultural area, a sightseeing agricultural area, and an education agricultural area, can be set up separately so that tourists can experience the enjoyment of rural agriculture when participating in some agricultural activities. It can certainly establish memorial and educational values while increasing local economic incomes. Rural tourism can also promote the sales of local agricultural products, making rural tourism and agricultural production mutually beneficial and supporting the sustainable economic development of rural areas. Wang and Deng proposed that agricultural production could be organized in accordance with the landscape characteristics with an emphasis on raising the value of local products [25]. We came to much the same conclusions and recommendations as stated above. However, our conclusion that the farmland landscape needs to be protected is different from the conclusion that 
Wang and Deng believe that case villages could abandon the farmland landscape when developing rural tourism. The difference might be due to the neglect of the importance of the farmland landscape in [25] and a different focus there.

(4) Suggestions for increasing the landscape value (B4). B4 includes the landscape type richness (C15), the landscape quantity richness (C16), the landscape uniqueness (C17), the landscape integrity (C18), the landscape artistic value (C19), and the landscape aesthetic value (C20). Among them, the landscape type richness (C15) and the landscape aesthetic value (C20) have the largest weights of evaluation and should be given priority in developing landscape tourism. Places such as ancient architecture, religious temples, and historical monuments are the natural spots for attracting tourists. Other types of the landscape can then be included to increase the variety. For example, public green spaces, small parks, public activity venues, and new landscape buildings could be built to meet the different needs of residents and tourists.

Our model also has certain limitations (for example, the indicators we selected might be more suitable for use in developing countries and regions), and the selection of indicators should follow the needs of rural development in each country or region. Different countries and regions have different development strategies and different needs for the value of rural landscape resources, so the specific contents for evaluation may be adjusted accordingly. However, the evaluation index system we established in this article can be generalized to evaluate the rural landscape projects in other situations. The evaluation results and suggestions can be important references for the local governments at all levels or third-party evaluation institutions to evaluate the performance of rural landscape projects managed by the local governments in the planning, design, transformation, development, and protection of the rural landscape.

Author Contributions: Writing—original draft preparation and investigation, W.L.; methodology, Y.Z.; conceptualization and supervision, G.X. All authors have read and agreed to the published version of the manuscript.

Funding: This research was funded by the Hunan Social Science Fund Project, grant number 18YBA453. This work was funded by [Philosophy and Social Science Foundation Project of Hunan Province of China], grant number [No. 18YBA453].

Informed Consent Statement: Not applicable.

Data Availability Statement: Not applicable.

Conflicts of Interest: The authors declare no conflict of interest. The funders had no role in the design of the study; in the collection, analyses, or interpretation of data; in the writing of the manuscript; or in the decision to publish the results.

\section{Appendix A}

Questionnaire for the evaluation of rural landscape resources

Dear Sir/Madam,

Thank you for supporting our survey.

The purpose of this survey is to study the current situation of rural landscape resources. Your answers will be of great help to our research and also the improvement of the value of rural landscape resources.

Please select

1. You are:

( ) an expert from landscape design firms

( ) a manager of landscape management department (landscape management bureau, planning bureau)

() a researcher in universities or institutes

() other

2. Your educational background:

( ) B.S./B.A ( ) M.S/M.A ( ) PhD ( ) Others 
3. How long have you been engaged in landscape research or practice?

( ) 3 years ( ) 4-10 years ( ) 11-15 years ( ) 16-20 years ( ) 20 years

4. According to your knowledge of the landscape of the countryside, please comment on the present situation of the following indicators. The score of each question ranges from 1 to 5 . The meanings of different scores are as follows: 1 is "very poor", 2 is "poor", 3 is "fair", 4 is "good", and 5 is "very good". Use a ' $\sqrt{ }$ ' to select your answer.

Evaluation object (village name): (Xiapu village)

\begin{tabular}{|c|c|c|c|c|c|c|}
\hline \multirow{2}{*}{$\begin{array}{l}\text { Dimensions of } \\
\text { Evaluation }\end{array}$} & \multirow{2}{*}{ Evaluation Index } & \multicolumn{5}{|c|}{ Dimensions of Evaluation } \\
\hline & & Very Poor & Poor & Fair & Good & Very Good \\
\hline \multirow{6}{*}{ Environmental value B1 } & Landscape ecological value $\mathrm{C} 1$ & & & & & \\
\hline & Landscape environmental protection degree $\mathrm{C} 2$ & & & & & \\
\hline & Environmental cleanliness degree C3 & & & & & \\
\hline & Environmental fusion degree $\mathrm{C} 4$ & & & & & \\
\hline & Geographical location value C5 & & & & & \\
\hline & Rural livability C6 & & & & & \\
\hline \multirow{5}{*}{ Social value B2 } & Attribution value $C 7$ & & & & & \\
\hline & Historical heritage value $\mathrm{C} 8$ & & & & & \\
\hline & Educational memorial value C9 & & & & & \\
\hline & Social popularity C10 & & & & & \\
\hline & Cultural value C11 & & & & & \\
\hline \multirow{3}{*}{ Economic Value B3 } & Agricultural production value $\mathrm{C} 12$ & & & & & \\
\hline & Rural tourism value $\mathrm{C} 13$ & & & & & \\
\hline & Sustainable development value C14 & & & & & \\
\hline \multirow{6}{*}{ Landscape value B4 } & Landscape type richness C15 & & & & & \\
\hline & Landscape quantity richness $\mathrm{C} 16$ & & & & & \\
\hline & Landscape uniqueness C17 & & & & & \\
\hline & Landscape integrity C18 & & & & & \\
\hline & Landscape artistic value C19 & & & & & \\
\hline & Landscape aesthetic value $\mathrm{C} 20$ & & & & & \\
\hline
\end{tabular}

We promise that the contents of the questionnaire will be kept strictly confidential and used only for academic research purposes. No specific units or individuals are involved in this survey.

Thank you for your support and cooperation,

Project Research Group

\section{References}

1. Recommendation CM/Rec(2021)11 of the Committee of Ministers to Member States for the Implementation of the Council of Europe Landscape Convention-Landscape and Agriculture. Available online: https://search.coe.int/cm/pages/result_details. aspx?objectid=0900001680a4a197 (accessed on 15 December 2021).

2. Agnoletti, M. Rural landscape, nature conservation and culture: Some notes on research trends and management approaches from a (southern) European perspective. Landsc. Urban Plan. 2014, 126, 66-73. [CrossRef]

3. Lv, W.; Ji, S. Atmospheric environmental quality assessment method based on analytic hierarchy process. Discret. Contin. Dyn. Syst. 2019, 12, 941. [CrossRef]

4. Rural Landscapes. Available online: https://www.asla.org/uploadedFiles/CMS/Government_Affairs/Public_Policies/Rural_ Landscapes.pdf (accessed on 23 November 2021).

5. Ana, L.U.; Cecilia, G.G.; Emilio MV, C.; Julieta, A.R.; Luis, G.B.; Mariana, B. Landscape heterogeneity of peasant-managed agricultural matrices. Agric. Ecosyst. Environ. 2020, 292, 106797.

6. Aslıhan, T.; Esra, Ö.; Meliha, A. Agricultural landscape pattern and agricultural tourism potential of Nevsehir. Akad. Ziraat Derg. $2018,7,245-252$. 
7. Xu, H.; Liu, C.; Yang, J.L. Construction of Henan Plain Rural Agricultural Landscape under Rural Revitalization. Landsc. Archit. 2020, 3, 82-87.

8. Yang, X.J.; Wang, A.P.; Dong, Q. Research on Evaluation Index System of Leisure Agricultural Landscape Based on AHP Method Chin. Agric. Sci. Bull. 2018, 34, 77-81.

9. Chen, X.H.; Yang, X.J. The construction model and method of leisure agricultural landscape under the background of rural revitalization-Taking Lishui area as an example. Oper. Manag. 2018, 12, 104-111.

10. Feng, X.H.; Dai, G.Q. Research on the Protection of Agricultural Landscape Characteristics in Rural Tourism Development. Tour. Trib. 2012, 8, 104-111.

11. He, J.B. On the Composition of Ecological Agriculture Landscape. J. Hunan Inst. Humanit. Sci. Technol. 2008, 6, 64-66.

12. Tang, Q.; Ding, S.Y. Multifunctional agricultural landscape: Connotation, progress and research paradigm. Acta Ecol. Sin. 2020, 40, 4689-4697.

13. Xie, X.L. An Exploration of Agricultural Landscape in Rural Landscape. Master's Thesis, Soochow University, Suzhou, China, 2015.

14. Boris, T.Z.; Peter, H.V.; Maria, E.; Sergio, G.Y.P.; Giuliano, G.; Jochen, K.; Martin, K.; Marianne, L.; Rosa, M.; Annette, P.; et al. European agricultural landscapes, common agricultural policy and ecosystem services: A review. Agron. Sustain. 2014, 34, 309-325.

15. Marianne, L.; Maria, E.; Sergio, G.P.; Maria, L.P.; Annette, P.; Ingo, Z. Agricultural landscapes as multi-scale public good and the role of the Common Agricultural Policy. J. Environ. Plan. Manag. 2015, 58, 2088-2112.

16. Marko, O.; Renata, S.E. Assessment of the European Common Agricultural Policy and landscape changes: An example from Slovenia. Agric. Econ. 2018, 65, 489-498.

17. Hu, M.; Zhang, Y. Landscape experience evaluation of Yunnan ethnic villages from the perspective of landscape narrative. Green Sci. Technol. 2021, 23, 6-11.

18. Fabiola, S.; Koji, H.; Hadi, A.; Komarsa, G.; Keiji, S. Practical application of a land resources information system for agricultural landscape planning. Landsc. Urban Plan. 2006, 79, 38-52.

19. Junge, X.; Schüpbach, B.; Walter, T.; Schmid, B.; Lindemann-Matthies, P. Aesthetic quality of agricultural landscape elements in different seasonal stages in Switzerland. Landsc. Urban Plan. 2015, 133, 67-77. [CrossRef]

20. Rosley, M.S.F.; Lamit, H.; Rahman, S.R.A. Perceiving the aesthetic value of the rural landscape through valid indicators. ProcediaSoc. Behav. Sci. 2013, 85, 318-331. [CrossRef]

21. Arriaza, M.; Cañas-Ortega, J.F.; Cañas-Madueño, J.A.; Ruiz-Aviles, P. Assessing the visual quality of rural landscapes. Landsc. Urban Plan. 2004, 69, 115-125. [CrossRef]

22. Lee, D.K.; Yoon, E.J.; Kim, E.Y.; Cho, S.J. A study on rural landscape assessment based on rural amenity resources. J. Korean Soc. Rural. Plan. 2007, 13, 11-17.

23. Yan, M.; Zeng, Q.H. Preliminary Study on the Evaluation Method of the Current Situation of Urban Landscape Resources. Sci. Technol. Inf. 2006, 2, 91-92.

24. Zhao, Y.W.; Yang, Y.J. Research on the Satisfaction Degree of Rural Tourism Planning Based on Fuzzy Comprehensive EvaluationA Case Study in Donghan Village, Hu County, Shaanxi. J. Hum. Settl. West China 2015, 4, 72-76.

25. Wang, Q.N.; Deng, H.F. AVC Theory Based Rural Landscape Evaluation: Taking Sancha Village as an Example. J. Northwest For. Univ. 2016, 31, 298-303.

26. Panek, M. The Effect of Agricultural Landscape Structure on Food Resources and Survival of Grey Partridge Perdix Perdix Chicks in Poland. J. Appl. Ecol. 1997, 34, 787-792. [CrossRef]

27. Li, D.; Meng, H.J. History of Computer Research and Development. J. Affil. Cloud Affil. Cloud Generator. 1995, 6, 15-20.

28. Li, Y.P.; Liu, M.Q.; Wang, F. Evaluation method of Cloud Model for safety performance of prefabricated construction projects. Chin. Saf. Sci. J. 2017, 27, 115-120.

29. Liang, R.; Wang, J.Q. A Linguistic Intuitionistic Cloud Decision Support Model with Sentiment Analysis for Product Selection in E-commerce. Int. J. Fuzzy Syst. 2019, 21, 963-977. [CrossRef]

30. Shi, Y.B.; Zhang, H.A.; Hou, H.Q. Summarize of electronic warfare systems engineering. Electron. Opt. Control. $2007,14,69-72$.

31. Liao, W.; Zang, Z.M.; Meng, X.C.; Li, Y. Application of Cloud theory in reliability assessment of combat aircraft. Comput. Simul. 2005, 22, 235-238

32. Bao, G.Y.; Lian, X.L.; He, M. Improved two-tuple linguistic representation model based on new linguistic evaluation scale. Control 2010, 25, 780-784.

33. Tversky, A.; Kahneman, D. Advances in Prospect Theory: Cumulative Representation of Uncertainty. J. Risk Uncertain. 1992, 5 , 297-323. [CrossRef]

34. Chen, S.X.; Wang, J.Q.; Wang, T.L. Cloud-based ERP system selection based on extended probabilistic linguistic MULTIMOORA method and Choquet integral operator. Comput. Appl. Math. Inf. Sci. 2019, 38, 88. [CrossRef]

35. Pang, Q.; Wang, H.; Xu, Z.S. Probabilistic linguistic term sets in multi-attribute group decision making. Inf. Sci. 2016, 369, 128-143. [CrossRef]

36. Kahneman, D.; Tversky, A. Prospect theory: An analysis of decision under risk. Econometric 1979, 47, 263-291. [CrossRef]

37. Yang, D.; Luo, T.; Lin, T.; Qiu, Q.; Luo, Y. Combining aesthetic with ecological values for landscape sustainability. PLoS ONE 2014, 9, e102437. [CrossRef] [PubMed] 
38. Wang, J.L.; Ran, Y.Y.; Zhang, Y.J.; Cao, X.M.; Yang, F. Land cover and landscape pattern changes in Poyang Lake region of China in 1980-2010. Chin. J. Appl. Ecol. 2013, 24, 1085.

39. Cai, Z.R.; Fang, C.Y.; Zhang, Q.; Chen, F.L. Joint development of cultural heritage protection and tourism: The case of Mount Lushan cultural landscape heritage site. Herit. Sci. 2021, 9, 86. [CrossRef]

40. Liu, R.; Xiao, J. Factors Affecting Users' Satisfaction with Urban Parks through Online Comments Data: Evidence from Shenzhen, China. Int. J. Environ. Res. Public Health 2021, 18, 253. [CrossRef] [PubMed]

41. Kristensen, S.B.P.; Busck, A.G.; van der Sluis, T.; Gaube, V. Patterns and drivers of farm-level land use change in selected European rural landscapes. Land Use Policy 2016, 57, 786-799. [CrossRef]

42. Dissanayake, D.; Morimoto, T.; Murayama, Y.; Ranagalage, M.; Handayani, H.H. Impact of Urban Surface Characteristics and Socio-Economic Variables on the Spatial Variation of Land Surface Temperature in Lagos City, Nigeria. Sustainability 2019, 11, 25. [CrossRef]

43. Ian, C.M.; John, H.; Sigrid, H.L.; Berna, K. Promoting urban greening: Valuing the development of green infrastructure investments in the urban core of Manchester, UK. Urban For. Urban Green. 2013, 12, 296-306.

44. Tengberg, A.; Fredholm, S.; Eliasson, I. Cultural ecosystem services provided by landscapes: Assessment of heritage values and identity. Ecosyst. Serv. 2012, 2, 14-26. [CrossRef]

45. Dupont, L.; Eetvelde, V.V. Assessing the potential impacts of climate change on traditional landscapes and their heritage values on the local level: Case studies in the Dender basin in Flanders, Belgium. Land Use Policy 2013, 35, 179-191. [CrossRef]

46. Irina-Maria, N.; George, E. Geolandscapes and Geotourism: Integrating Nature and Culture in the Bucegi Mountains of Romania. Landsc. Res. 2015, 40, 486-509.

47. Enslin, P. Monuments after Empire? The Educational Value of Imperial Statues. J. Philos. Educ. 2020, 54, 1333-1345. [CrossRef]

48. Prakash, K. Power asymmetries and institutions: Landscape conservation in central India. Reg. Environ. Chang. 2016, 16, 97-109.

49. Janet, S. The Cultural Values Model: An integrated approach to values in landscapes. Landsc. Urban Plan. 2007, 84, 127-139.

50. Tieskens, K.F.; Schulp, C.J.; Levers, C.; Lieskovský, J.; Kuemmerle, T.; Plieninger, T.; Verburg, P.H. Characterizing European cultural landscapes: Accounting for structure, management intensity and value of agricultural and forest landscapes. Land Use Policy 2017, 62, 29-39. [CrossRef]

51. Mara, T.; Yacov, T. Agricultural Landscape Value and Irrigation Water Policy. J. Agric. Econ. 2013, 64, 641-653.

52. Kaswanto, N.N. Land suitability for agrotourism through agriculture, tourism, beautification and amenity (ATBA) method. Procedia Environ. Sci. 2015, 24, 35-38. [CrossRef]

53. Cerreta, M.; Inglese, P.; Malangone, V.; Panaro, S. Complex values-based approach for multidimensional evaluation of landscape. In Proceedings of the International Conference on Computational Science and Its Applications, ICCSA 2014: Computational Science and Its Applications, Guimarães, Portugal, 30 June-3 July 2014; Springer International Publishing: Basel, Switzerland, $2014 ;$ pp. $382-397$.

54. Oehri, J.; Schmid, B.; Schaepman-Strub, G.; Niklaus, P.A. Terrestrial land-cover type richness is positively linked to landscape-level functioning. Nat. Commun. 2020,11, 154. [CrossRef]

55. Zelinsky, W. The Uniqueness of the American Religious Landscape. Geogr. Rev. 2001, 91, 565-585. [CrossRef]

56. Asrina, M.; Gunawan, A.; Aris, M. Identification of Minangkabau Landscape Characters. IOP Conf. Ser. Earth Environ. Sci. 2017, 91, 012018. [CrossRef]

57. Walston, L.J.; Hartmann, H.M. Development of a landscape integrity model framework to support regional conservation planning. PLoS ONE 2018, 13, e0195115. [CrossRef] [PubMed]

58. Rasouli, S.; Farkhondeh, F.M.; Jafari, H.R. Assessment of Ecological integrity in a landscape context using the Miankale peninsula of Northern Iran. Int. J. Environ. Res. 2012, 6, 443-450.

59. Chen, Y.; Jeannie, S.; Gillian, L. Deciphering Historic Landscapes: A Case Study of Slender West Lake in Yangzhou, China. Landsc. Res. 2016, 41, 95-112.

60. Tribot, A.S.; Deter, J.; Mouquet, N. Integrating the aesthetic value of landscapes and biological diversity. Proc. Biol. Sci. 2018, 285, 20180971. [CrossRef]

61. Wang, X.K.; Wang, Y.T.; Zhang, H.Y.; Wang, J.Q.; Li, L.; Goh, M. An asymmetric trapezoidal cloud-based linguistic group decision-making method under unbalanced linguistic distribution assessments. Comput. Ind. Eng. 2021, 160, 107457. [CrossRef]

62. Regional Overview. Available online: http://www.huidong.gov.cn/dzzrmzf/dzz/content/post_706114.html (accessed on 9 July 2021).

63. Huidong Promoted Poverty Alleviation with Distinctive Features According to Village Conditions, and 16 Provincial PovertyStricken Villages Were Lifted out of Poverty. Available online: http://www.huidong.gov.cn/hdxwz/zwgk/zwdt/zwyw/ content/post_4140128.html (accessed on 12 July 2021).

64. Huidong County People's Government Local annals Office. Huidong County Annals, 1st ed.; China Publishing House: Shanghai, China, 2003

65. Čurović, Ž.; Čurović, M.; Spalević, V.; Janic, M.; Sestras, P.; Popović, S.G. Identification and Evaluation of Landscape as a Precondition for Planning Revitalization and Development of Mediterranean Rural Settlements—Case Study: Mrkovi Village, Bay of Kotor, Montenegro. Sustainability 2019, 11, 2039. [CrossRef] 